\title{
Inside / Outside
}

\section{Review of 'Cybersemiotics: Why Information Is Not Enough', By Søren Brier, University of Toronto Press, 2008, 477 pages}

\author{
Stanley N. Salthe
}

Received: 15 October 2008 / Accepted: 12 November 2008 /

Published online: 6 May 2009

(C) Springer Science + Business Media B.V. 2009

Søren Brier is a thinker who seems to have come to Peircean semiotics because of anxiety about the fact that cognitive science lacks contact with subjectivity. From another point of view, I myself have considered that this semiotic approach might provide a way to expand science more generally away from its mechanistic habits. Brier's book attempts to examine texts related to information science from a Peircean semiotic perspective, with a view towards better understanding, or possibly even subverting, Cartesian dualism. For this purpose he examines the cognitive science-autopoietic and ethological discourses as reflecting one branch of science's nearest approach to mentality; neurology is not given significant attention. But the attempt reaches a stalemate as the book closes upon what I would call the internalism / externalism complementarity. Charles Peirce asserted that feeling is an integral aspect of the world generally, and hinted as well that it could be transformed into mattergy, but science, in its Twentieth Century eagerness to serve technology, has dismissed such ideas as 'pseudoscience'. Brier does not examine possibilities opened up by quantum mechanics on this issue (e.g., Laszlo 1995), although Penrose's thinking is mentioned from time to time. While Brier does not succeed in 'squaring' the Cartesian 'circle', he circles around the project vigorously, returning again and again to the quest (redundancy works!) while taking the reader on a long trek in search of this grail. This is an extremely rich text, and my focus here upon a few of its important points will not do it justice overall.

The major problem driving the inquiry in this book is signaled by the subtitle: "Information Is Not Enough" (to understand understanding). To this end Brier proposes to meld together classical science, systems and cybernetic science, and Peircean semiotic in his 'cybersemiotic model', laid out in a final chapter. The incommensurability or incompatibility of the internalist and externalist perspectives (subjective / objective; conscious experience / information processing; res cogitans / res extensa) is in my view the overriding reason for the existence of this book, 
which, however, manages to cover a good deal of related discursive ground as it unfolds. It is a valuable introduction to the information, cybernetic, autopoietic and associated systems-style literatures, as well as containing a nice review of Peircean semiotic.

In several long chapters Brier interrogates the systems-cybernetic "information processing" perspective, elaborately inquiring to what degree this approach makes contact with the experienced feelings of qualia. He has chapters on Gregory Bateson's thinking, on that of Maturana (and Varela), on von Foerster, and on Niklas Luhmann. This systems-cybernetic-autopoietic tradition, exhaustively unpacked in detail, and mapped to neat diagrams, is matched rather less intensely against the tradition of phenomenology (i.e., Husserl to Merleau-Ponty) without finding any substantial connection between the two. This lack of connection to phenomenology figures prominently as well in a chapter on ethology, tracking from von Uexküll through Konrad Lorenz to Iven Reventlow. Brier's earstwhile profession of information management has served him well, being called upon to bring in many supporting and elaborating viewpoints of numerous other authors (e.g., Churchland, Fodor, Lakoff, Wittgenstein) bearing upon this inquiry. Brier takes the ideas of these various authors and works with them instead of just setting them out. He is skillful in combining the ideas of many into a single whole. I think we can say that he has exhaustively demonstrated in what way cybernetics and associated systems perspectives fail to make contact with First Person, present progressive experience.

This is where Brier proposes that Charles Peirce's thought might come in, because Peirce's metaphysics has feeling involved (in the "Firstness" category of his metaphysical triad) in all situations and occasions. Thus, it could be said from this perspective that the cyberneticians have simply left something out. This, of course, is really not surprising given that they were making explicit models in the logical scientific mode, and stated as well in the Third Person, universal present tense. This is a mechanistic tradition that one can at once feel is not closely related to ongoing internal experience. Brier "want[s] to see whether it is possible to couple systems theory with Peircean triadic and pragmaticistic semiotics" (p. 250). In Peirce's thinking, "The inner life potentially exists[s] from the beginning but require[s] a nervous system in order to achieve [its] full manifestation" (P. 276). He suggests that ethology could serve as a bridge between Sebeok's biosemiotics and the information exchange discourses. Thus, Peircean triadism might provide a framework for bringing feeling into relation with physical and material understandings. In this view Brier implies that semiosis involves some degree of mentality. This, I think, is debatable. Certainly Marcello Barbieri's biosemiotics (Barbieri 2008) is nonmentalistic, and my own proposals (Salthe 2005, 2008a) are not meant to do more than bring contextuality, as mediation, into natural science. Yet, if emergents preexist their emergence in vague form (Salthe 2008b), my own view may not be so different from Brier's. In an evolutionary perspective, mentality would then be viewed as emerging from contextuality in systems that achieve significant complexity, and so cognition could be seen to be 'effete' contextuality, which itself would be 'effete' feeling.

As it happens, the organization of Brier's thinking-his 'cybersemiotic framework'-informally deployed throughout this book, is a structure that I have been concerned with for some time, which I label the 'specification hierarchy' (e.g., 
Salthe 1993, 2002), and so it seems that I am well suited to comprehend this book. This structure is logically a 'subsumptive hierarchy', where the more general, or more generally present, levels subsume all the more particular levels. Thus, e.g.:

\section{\{physical dynamics $\{$ material connectivities(biological forms $\}$ \}}

The brackets here are those used in set theory, and so the elements within them are classes, as in 'the class of physical dynamics'. The levels here are referred to variously as 'levels of reality' (Poli 1998), 'ontological levels' (e.g., Brier), or, more interestingly, 'integrative levels' (Needham 1943; Salthe 1993), and other labels as well. The lowest level (here, the realm of physics) subsumes all the others, while the highest level (here, biological systems) locally integrates the others under its own rules (Polanyi 1968). Table 1 provides an exercise in understanding the specification hierarchy.

In this hierarchical framework Brier's thinking can be displayed succinctly as in Table 2, which I suggest ought to be contemplated for a period of time that it would take to read a couple of pages of text. Here we have six specification hierarchies aligned one above the other so that they can be roughly coordinated. The top one displays Peirce's metaphysical categories, relating them to each other. Next we have the realms of the studies of various sciences, aligned from that which is most generally present in nature (on the left) up to the most particular subject realm (on the right). Then we have the subject matters of these sciences aligned roughly alongside the realms where they are studied. Below this is a hierarchy of scientific approaches dealing with the realms and subject matters shown above it. The next specification hierarchy shows the relations among the Aristotelian causal categories, deployed to show where they are most prominent in the studies shown in the upper hierarchies. Finally we have a hierarchy matching the kind of semiosis involved in the levels shown in the upper hierarchies. This final hierarchy, when coordinated with the others, suggests the temporal sequence of the emergence of higher-level semioses during Earth's history, and, more generally the implied sequence of emergence of the other labeled concepts in the table.

Because Brier's text relates prominently to the diremption between internalism and externalism, I find in doing this review an opportunity to raise an issue concerning the Peircean metaphysical triad, Firstness, Secondness and Thirdness.

Table 1 Several meanings of the specification hierarchy format

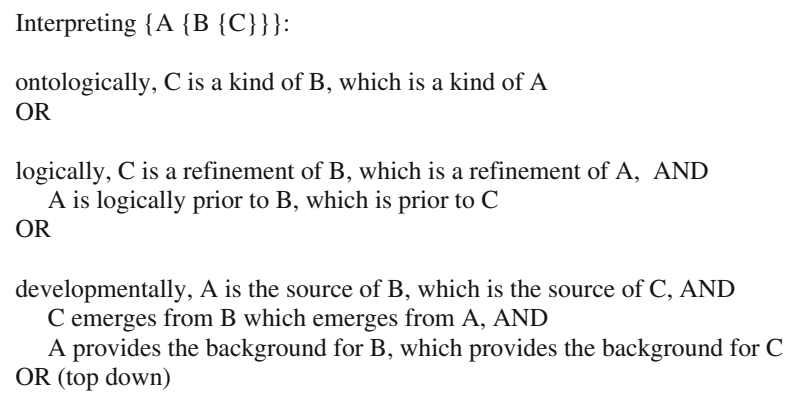


Table 2 The organization of Brier's thinking as represented in a series of six parallel specification hierarchies. The Peircean metaphysical categories and the Aristotelian causal categories are intended to be applicable at all levels, but could be viewed as becoming prominent in the levels indicated by the proposed coordination. The brackets bounding the levels have the same formal meaning as in set theory, here demarcating classes. Their coordinative placement relative to those in the other hierarchies is not meant to be precise. Development, where appropriate, would occur from left to right in the hierarchy. This table could be considered to symbolize the embodiment of knowledge

\{ First, feeling, caprice $\{$ Seconds, encounters $\{$ Thirds, externalization, fixation, habit $\}\}\}$

These could said to be acknowledged in discourses about:

\{quantum physics $\{$ physical chemistry $\{$ dissipative structures $\{$ life $\{$ cognition, consciousness $\}\}\}\}\}$

$\{$ motion, transitions $\{\quad$ information $\quad\{$ meaning $\{$ knowledge $\}\}\}\}$

$\{$ systems theory $\{$ cybernetics $\{$ autopoiesis $\{$ second order cybernetics $\}\}\}\}$

$\{$ material causes $\{$ efficient causes $\{$ formal causes $\{$ final causes $\}\}\}\}$

The development of semiosis as viewed in Brier's text

$\{$ protosemiosis / physiosemiosis $\{$ biosemiosis $\{$ semiosis $->$ quasisemiosis $\}\}\}$

The general meanings of these categories are clear enough, and I have not noticed in this book or elsewhere, nor have I felt, any controversy concerning them, and Brier's use is standard. However, their assignment to the semiotic triad of object, sign, interpretant, is, I believe, a matter for discussion. Brier follows the usage of most semioticians in assigning First to the sign, Second to the object and Third to the interpretant. This, following (most interpretations of) Peirce, seems to have become standard, but I think it needs to be problematized if semiotics is to be taken seriously by the information processing discourses, or by science in general. The issue is one, I think, of idealism as against materialism.

From a materialist perspective, the assignment of First to the representamen is not intelligible. While all three categories would in principle be present simultaneously in all situations, there is a sense of First being - first!, in some sense a primordial ground, even if it is temporally synchronic with the other categories in many applications. A materialist cannot feel the justness of a sign that 'stands for' something to some other entity [“... whereby a first and a second are brought into relation..." (Peirce CP, 6.32-3)] implicitly antedating that which it stands for. This problem might perhaps be finessed by deconstructing the object, beginning with the Umwelt concept of von Uexküll (1926) and moving into social constructivism (which Brier touches upon occasionally) by way of operationalism in physics (Bridgman 1927). But this I think will not 'wash' in most natural science discourses. For them, positioned as they are external to any investigated system, clearly the object (which could be a process or relationship) would need to be First, and, furthermore, it needs to be confronted by a material / physical system of some kind if it is to be interpreted. This is why I have advanced the 'system of interpretance' (Salthe 1998, 2008a, Fig. 1) as the creator of interpretants and as co-creator, with the object, of the sign, which then becomes Third. The confrontation / interaction between the object and the system of interpretance then generates the Secondness that produces interpretants. There are passages in Brier's book, even some quotes from Peirce himself, which could be cited to suggest this understanding (obviously I 
was looking for them!). Additionally, Brier often refers to the necessity to bring the observer explicitly into our thinking about cognition. The materialist point of view on this is that signs, being co-constructed by the object and the system of interpretance, could not possibly be the same for different observers (viz, von Uexküll), and therefore, if it is to be First, the sign must be an indefinitely multiple potentiality rather than an actuality. Again, this would be incoherent with the externalist stance of science (with the possible exception of a quantum physics cut loose from experimental designs?).

Might it be that the central problem addressed in Brier's book hinges semiotically upon the assignment of First or Third to the representamen? Internally, as viewed from any actual ongoing First Person experience, a sign could intelligibly be First, but externally, as viewed by an investigating Third Person, the sign would be elucidated by experimental observations to be Third, as a result of semiosis. Since these positions, being fully explicit, are incommensurable, we can see clearly that, while First, Second and Third are useful categories, and while the sign-interpretant-object triad is central to Peircean semiotics, the relation between these two formats needs to become an object of investigation rather than a rigid template in the idealist mode. And I think Brier's elaborate worrying of the First Person / Third Person incompatibility provides a natural ground for suggesting the need to take up this issue within semiotics.

A major bias of most of the approaches dealt with in this work is that they are basically synchronic in spirit. This includes most appreciations of Peirce's work, despite his 'evolutionary' metaphysics (e.g., Esposito 1980, Hausman 1993). Brier frequently invokes von Foerster's use of the 'eigenvalue' concept, as standing for the condition a system will get to in the long run if it continues working as it is doing now - that is, if it doesn't change, or change direction. Far from criticizing this bias, I think that a non-evolutionary perspective is quite natural in a work devoted to searching for a discursive way into First Person subjectivity. There is no felt time in inner experience (Matsuno and Salthe 2002), where its precursor exists only as a continually unfolding unified feeling of memory-now-anticipation. And this is the case despite the fact that an internal experience could be tracked externally, as a brain process occurring in the moments of sidereal time. In science, 'before' and 'after' have been crucial distinctions triggered by efficient causation, even though the resulting texts are reported in a timeless universal present tense (Kampis 1991). If something is reported as changing, it would be shown as changing in a constitutive way characteristic of a kind of investigated system-thus, as developing (Salthe 1993), or as a property (Brenner 2008). Actual change (evolution) is relegated to history. The latter, as such, is not on Brier's agenda. Even when dealing with many of the contributions to the cybernetic-information discourse by different workers, his approach is not historical, but rather attempts to show how different workers enrich a general idea with their separate contributions, much as the proverbial blind men construct the elephant simultaneously.

Now we might briefly consider whether science would gain anything from taking up a Peircean semiotic perspective. Brier demonstrates its possible usefulness in library and information science as a source of classifications (even though his own diagrams are quadratic rather than triadic). But in science's social role as promoter of technology, there does not seem to me to be an obvious role for semiotics. This 
might change if contextuality is taken up by those sciences trying to deal with complexity. With the possible exception of Barbieri's (2008) non-mentalist version of semiotics, focusing upon coding as a material process, it seems to me that semiotics has, at present, mostly philosophical rather than technological implications. This philosophical role is important in its own right given that, despite opinions to the contrary, Descartes' dualism between mentality and material extension (and physical intension) still stands. Even if conscious moods arise as artifacts of coded construction (Barbieri 2006), these moods are as different from the coding process as phenotype generally (including the ribosomal apparatus) is different from genotype. Cartesian dualism, like the epistemic cut between observer and observed (Pattee 2001) still stands! "Cognitive phenomena can be explained either with functionalist-cybernetic or with meaning-based semiotic approaches, but neither provides a complete explanation." (P. 403). Attempts to get to the subject by way of objective analyses will only result in moving subjectivity into smaller and smaller corners of an increasingly elucidated model of a system. This image is cogent because subjectivity, no matter how it is produced, has no extension. I believe, for example, that no scientist or analytical philosopher could advance reasons against the notion that the internal experience of, say, a hummingbird, would be very like our own despite its comparatively restricted range of conceptual categories. If internity had extension, then, e.g., gyrating flocks of starlings could be said to exemplify intersubjectivity.

"It is my hope that the cybersemiotic theory of meaning and mind can integrate classical scientific thinking and the functionalistic thinking of systems and cybernetics with the evolutionary framework and finally with the phenomenological analysis of mind as found in Merleau-Ponty." (Page 429). One failing of discursive attempts to grapple with the relationship between internity and externity is that these attempts - text and diagrams - are always as fully explicit as possible, while internity is in fact something different from that. Taking a cue from Peirce, I think it important to see that the indefinite and the definite must arise from a precursor Firstness that is vague. Vagueness is a condition that only poets deal with discursively, by way of indirection. Brier could have worked even harder, bringing in all of neurology and psychiatry and Eastern philosophy, and he still would not have 'squared' the Cartesian 'circle'. Perhaps we need to take Peirce's advice (1905) and try to construct a logic of vagueness.

\section{References}

Barbieri, M. (2006). Semantic biology and the mind-body problem: the theory of the conventional mind. Biological Theory, 1, 352-356.

Barbieri, M. (2008). Biosemiotics: a new understanding of life. Naturwissenschaften, 95, 577-599.

Brenner, J. E. (2008). Logic in reality. New York: Springer.

Bridgman, P. W. (1927). The logic of modern physics. New York: Macmillan.

Esposito, J. L. (1980). Evolutionary metaphysics: The development of Peirce's theory of categories. Athens: Ohio University Press.

Hausman, C. R. (1993). Charles S, Peirce's evolutionary philosophy. Cambridge, UK: Cambridge University Press.

Kampis, G. (1991). Self-modifying systems in biology and cognitive science: A new framework for dynamics, information and evolution. London: Pergamon Press. 
Laszlo, E. (1995). The interconnected universe: Conceptual foundations of transdisciplinary unified theory. Hong Kong: World Scientific.

Matsuno, K., \& Salthe, S. N. (2002). The origin and development of time. International Journal of General Systems, 31, 377-393.

Needham, J. (1943). Integrative levels: A revaluation of the idea of progress. In J. Needham (Ed.), Time: The resfreshing river. London: George Allen \& Unwin.

Pattee, H. H. (2001). The physics of symbols: bridging the episemic cut. BioSystems, 60, 5-21.

Peirce, C. S. (1905). Issues of pragmatism. The Monist, 15, 481-499.

Peirce, C.S. (1931-1958) Collected Papers. Vols. I - VIII. C. Hartshorne and P. Weiss (eds.) Cambridge, MA: Harvard University Press.

Polanyi, M. (1968). Life's irreducible structure. Science, 160, 1308-1312.

Poli, R. (1998). Levels. Axiomantes, 9(1-2), 197-211.

Salthe, S. N. (1993). Development and evolution: Complexity and change in biology. Cambridge, MA: MIT Press.

Salthe, S. N. (1998). Semiosis as development. In J. Albus \& A. Meystel (Eds.), Proceedings of the 1998 IEEE ISIC / CRA / ISAS, on intelligent systems, pp. 730-735. Gaithersberg: IEEE Press.

Salthe, S. N. (2002). Summary of the principles of hierarchy theory. General Systems Bulletin, 31, $13-17$.

Salthe, S. N. (2005). Meaning in nature: placing biosemiotics within pansemiotics. Journal of Biosemiotics, 1, 211-221.

Salthe, S.N. (2008a) The system of interpretance, naturalizing meaning as finality. Biosemiotics http://dx. doi.org/10.1007/s12304-008-9023-3

Salthe, S.N. (2008b) Development (and evolution) of the universe. Evo Devo Universe conference paper. von Uexküll, J. (1926). Theoretical biology. London: Harcourt, Brace. 